\title{
Notes sur les auteurs
}

Olga Anna Duhl est professeur de langue et littérature françaises à Lafayette College (États-Unis). Spécialiste du théâtre des XVe et XVI ${ }^{\mathrm{e}}$ siècles (Folie et rhétorique dans la sottie, Genève, Droz, 1994 ; Le théâtre français des années 1450-1550 [éd.], Dijon, Université de Bourgogne, «Le Texte et l'Édition », 2002 ; La Sotise a huit personnaiges (Le Nouveau Monde), édition critique, Genève, Droz, à paraître), elle a publié également des études de littérature comparée portant sur les domaines italien, britannique, latin, ainsi que sur la réception des œuvres de François Rabelais à la fin du $\mathrm{XIX}^{\mathrm{e}}$ siècle. Elle prépare actuellement une édition critique de la Nef des folles (vers 1498), œuvre de Josse Bade traduite du latin en français par Jehan Droyn.

Brenda Dunn-Lardeau est professeur titulaire au Département d'Études littéraires à l'Université du Québec à Montréal. Au nombre de ses ouvrages et directions d'ouvrages sur le Moyen Âge et la Renaissance, on compte le volume d'Actes «Legenda aurea »: sept siècles de diffusion (1986) ; l'édition critique de Jacques de Voragine, La légende dorée, dans la révision de 1476 par Jean Batallier, d'après la traduction de Jean de Vignay (1333-1348) de la Legenda aurea (c. 1261-1266) (1997), ouvrage couronné par l'Académie française en 1998 et la MLA en 1999 ; les Actes d'Entre la lumière et les ténèbres. Aspects du Moyen Âge et de la Renaissance dans la culture des XIX et XX $X^{e}$ siècles (1999); Le saint fictif. L'hagiographie médiévale dans la littérature contemporaine (1999) ; la direction de Portraits du bonheur au Moyen Âge et à la Renaissance. Douze modèles de félicité céleste et terrestre, $\mathrm{n}^{\mathrm{O}}$ spécial de Memini (2002), ainsi que l'édition de Jehan Du Pré, Le Palais des Nobles Dames (Lyon, 1534), 2003 (sous presse). 
Jelle Koopmans enseigne la littérature française du Moyen Âge à l'Université d'Amsterdam où il dirige le projet de recherche «Cultures régionales et sub-cultures locales : mondes du théâtre français, 1450-1550». Il est auteur d'éditions critiques (sermons joyeux, Condamnation de Banquet, Mystère de saint Remi) et de monographies (Sermon joyeux et truanderie, Le théâtre des exclus) et il prépare une édition critique des farces du Recueil de Florence.

Barbara Marczuk, docteur ès Lettres, est maître de conférences à l'Université Jagellonne de Cracovie (littérature française du seizième siècle). Elle a publié sa thèse L'inspiration biblique dans l'œuvre de Marguerite de Navarre (Cracovie, Universitas, 1992) et l'édition critique des Comédies bibliques de Marguerite de Navarre (Genève, Droz, 2000). Elle a aussi fait paraître une traduction en polonais des histoires tragiques des $\mathrm{XVI}^{\mathrm{e}}$ et XVII ${ }^{\mathrm{e}}$ siècles (Krwawy Amfiteatr, Cracovie, Universitas, 2002). Ses recherches actuelles portent sur la problématique des passions dans les narrations au féminin à la Renaissance.

Charles Mazouer est professeur de littérature française à l'université Michel de Montaigne - Bordeaux III depuis une trentaine d'années. Agrégé de Lettres classiques, Docteur d'État, il est spécialiste de l'ancien théâtre français, du Moyen Âge au XVIII' siècle. Il a consacré une bonne part de son activité à l'édition critique de textes de l'ancien théâtre (tragédies de Garnier, comédies de R. Poisson, Regnard, le théâtre italien de Gherardi, les farces du XVII ${ }^{\mathrm{e}}$ siècle... ). Il a entrepris, pour les éditions Champion, une grande histoire du théâtre français, du Moyen Âge au XXI ${ }^{\mathrm{e}}$ siècle, et dirige pour ce projet une équipe d'une dizaine d'historiens du théâtre. Ses dernières publications sont les suivantes : Molière et ses comédies-ballets (Paris, Klincksieck, 1993) ; Le Théâtre français du Moyen Âge (Paris, SEDES, 1998); Trois Comédies de Molière. Étude sur «Le Misanthrope», « George Dandin », «Le Bourgeois gentilhomme » (Paris, SEDES, 1999); Le Théâtre français de la Renaissance (Paris, Champion, 2002) ; Le Théâtre d'Arlequin. Comédies et comédiens italiens en France au XVIIe siècle (Fasano, Italie - Paris, Schena et Presses de l'Université de Paris - Sorbonne, 2002).

Régine Reynolds-Cornell est professeur émerite et chevalier dans l'ordre des Palmes académiques. Professeur assistant, puis associé à Southwestern University, elle a ensuite été titulaire de la chaire « Adeline Arnold Loridans » et professeur à Agnes Scott College à Atlanta (États-Unis). Outre ses travaux d'édition sur le théâtre du XVI ${ }^{\mathrm{e}}$ siècle publiés par les Presses Universitaires de France, elle s'est tout particulièrement intéressée à Marguerite de Navarre (Les devisants de l'Heptaméron. Contribution à l'étude 
de la pensée politique et sociale de Marguerite de Navarre; Les devisants de l'Heptaméron. Dix personnages en quête d'audience ; La rhétorique du silence dans le théâtre de Marguerite de Navarre; Marguerite de Navarre's Théâtre Profane, traduction en anglais des farces et comédies ; Colloque international pour le $500^{\mathrm{e}}$ anniversaire de Marguerite de Navarre, etc.). Elle s'est aussi penchée sur les œuvres de femmes auteurs qu'elle place dans leur contexte historico-social. Parmi celles-ci, Jeanne Flore, dont sa nouvelle édition des Contes amoureux est prévue pour 2005 (Textes et Contre-textes, Université de Saint-Etienne), Nicole Liebault (Bibliothèque d'Humanisme et Renaissance), Georgette de Montenay (Summa), Anne-Marguerite Petit du Noyer (Gunter Nar Verlag, Tübingen).

Colette H. Winn est professeur de langue et de littérature françaises à Washington University, Saint Louis, États-Unis. Elle est l'auteur des éditions critiques suivantes : Gabrielle de Coignard, Euvres chrestiennes, Droz, 1995 ; Madeleine de l'Aubespine (attribue à), Cabinet des saines affections, H. Champion, 2001 ; Marie Le Gendre, Exercice de l'âme vertueuse, $\mathrm{H}$. Champion, 2001 ; Protestations et revendications féminines, textes inédits et oubliés sur l'éducation féminine (XVI $-\mathrm{XVII}{ }^{\mathrm{e}}$ siècles); L'Album de la Mareschale de Retz (avec François Rouget), H. Champion, 2004 ; Le verger fertile des vertus composé par defuncte Madame de Verger (avec Susan Broomhall), H. Champion, 2004. Elle a collaboré à l'édition des volumes collectifs suivants : L'éducation des filles sous l'Ancien Régime (vol. dédié à la memoire de Linda Timmermans), Papers on French Seventeenth-Century Literature, 24, ${ }^{\circ}$ 46, 1997 ; Women Writers in PreRevolutionary France (avec Donna Kuizenga), Garland Publishing, 1997 ; Writings by Pre-Revolutionary French Women (with Anne R. Larsen), Garland Publishing 2000 ; Ronsard : Figure de la variété : en mémoire d'Isidore Silver, Travaux d'Humanisme et Renaissance 368, Droz, 2002 ; Veufs, veuves et veuvage dans la France d'Ancien Régime (avec la collaboration de Nicole Pellegrin), H. Champion, 2003 ; Lettres de femmes (XVI ${ }^{\mathrm{e}}-\mathrm{XVIII}{ }^{\mathrm{e}}$ siècles) (avec Elizabeth Goldsmith, à paraître prochainement). 